\title{
Flow-Through Quantification of Microplastics Using Impedance Spectroscopy
}

\author{
Beckett C. Colson and Anna P. M. Michel*
}

Cite This: ACS Sens. 2021, 6, 238-244

Read Online

ABSTRACT: Understanding the sources, impacts, and fate of microplastics in the environment is critical for assessing the potential risks of these anthropogenic particles. However, our ability to quantify and identify microplastics in aquatic ecosystems is limited by the lack of rapid techniques that do not require visual sorting or preprocessing. Here, we demonstrate the use of impedance spectroscopy for highthroughput flow-through microplastic quantification, with the goal of rapid measurement of microplastic concentration and size. Impedance spectroscopy characterizes the electrical properties of individual particles directly in the flow of water, allowing for simultaneous sizing and material identification. To demonstrate the technique, spike and recovery experiments were conducted in tap water with 212-1000 $\mu \mathrm{m}$ polyethylene beads in six size ranges and a variety of similarly sized biological materials. Microplastics were reliably detected, sized, and differentiated from biological materials via their electrical properties at an average flow rate of $103 \pm 8 \mathrm{~mL} / \mathrm{min}$. The recovery rate was $\geq 90 \%$ for microplastics in the $300-1000 \mu \mathrm{m}$ size range, and the false positive rate for the misidentification of the biological material as plastic was $1 \%$. Impedance spectroscopy allowed for the identification of microplastics directly in water without visual sorting or filtration, demonstrating its use for flow-through sensing. KEYWORDS: microplastics, plastics, impedance spectroscopy, dielectric properties, instrumentation, particle detection, flow-through, environmental sensing

$\mathrm{M}$ icroplastics are ubiquitous in the environment, but it is difficult to assess the risks to ecosystems without understanding the fate and transport of microplastics. ${ }^{1-7}$ Microplastics are challenging to measure because of variation in polymer type, size, shape, concentration, persistence, and matrix. ${ }^{3,8,9}$ Field analyses, especially in aquatic environments, are limited by current techniques, which are ex situ, timeconsuming, require expensive equipment, and lack interlaboratory comparability. ${ }^{10-13}$ In aquatic environments, microplastics from point ${ }^{14-16}$ and diffuse ${ }^{17,18}$ sources are transported by processes with wide spatial and temporal scales. ${ }^{14,15,19-23}$ High-throughput, in situ techniques are needed to quantify microplastics in aquatic environments, enabling the transport dynamics of the microplastics to be captured and the microplastic sources to be tracked.

For high quality observations, a technique must differentiate microplastics from natural materials. Often, visual identification is used to separate microplastics from natural materials, $^{13,24}$ but significant misidentification errors can occur. ${ }^{10,13,25-28}$ Nile Red can aid in the detection of microplastics, ${ }^{29,30}$ but biological particles can cause false detections. $^{31,32}$ The microplastic type can be identified with Raman spectroscopy, including Raman microspectroscopy $^{25,26,33}$ and Raman imaging, ${ }^{34-36}$ or with Fourier transform infrared (FTIR) spectroscopy, including attenuated total reflection-FTIR (ATR-FTIR) ${ }^{28,33,37,38}$ and FTIR imag- ing, ${ }^{16,34,35,39-43}$ or with pyrolysis gas-chromatography massspectrometry. ${ }^{38,44,45}$ These polymer identification techniques are time-consuming and require expensive equipment. ${ }^{12,13}$ To reduce the analysis time, a visual identification step or subsampling is often used, which can cause nonrepresentative results. $^{13,25,34,35,42,43}$ Portable pyrolysis-mass spectrometry is rapid ( $5 \mathrm{~min}$ ), but the biological material can interfere with the analysis, and particles are not individually quantified. ${ }^{46}$ Flowthrough microplastic detection via Raman spectroscopy achieves higher throughput but cannot count microplastics accurately because the flow through the sensor is only partially analyzed. $^{47-49}$ Biological particles can also interfere with Raman measurements. ${ }^{47}$ Pollard et al. recently demonstrated the use of a flow-through resistive pulse sensor to detect microplastics shed from tea bags and differentiate them from rod and spherical algae. ${ }^{50}$

We propose impedance spectroscopy for high-throughput flow-through measurement of microplastics due to its low

Received: October 23, 2020

Accepted: December 23, 2020

Published: January 9, 2021 
cross-sensitivity to biological particles. The overall goal is to demonstrate this technique for detecting and counting the number of microplastics present in an aqueous solution. The secondary goal is to demonstrate its utility for sizing the microplastics as they are detected. In flow cytometry applications, impedance spectroscopy is used to infer the electrical properties of single cells at high-throughput, ${ }^{51-61}$ with recent results differentiating red blood cells and plastic beads at 200 cells $/ \mathrm{s}^{61}$ Electrodes monitor the impedance change as particles pass in a flowing medium, such as phosphate-buffered saline, ${ }^{51,53,58,60,61}$ tap water, $^{62,63}$ or saltwater. ${ }^{64}$ Following Ohm's law, the impedance relates a voltage source to the magnitude and phase of current passing through a circuit element as a function of frequency. ${ }^{5,58-60}$ At low frequency, the impedance change is proportional to a particle's volume and is used in Coulter counters for sizing. $^{51-54,56-58,61,62,65}$ At higher frequencies, particle internal properties may be measured, such as the membrane capacitance or cytoplasm conductivity. ${ }^{51-54,56-62,65}$ Impedance spectroscopy has been applied to blood analysis, ${ }^{53,61}$ tumor cell identification, ${ }^{66}$ bacteria detection, ${ }^{62}$ and plankton discrimination. ${ }^{64}$ Plastic beads, which are used for testing and size calibration, are routinely differentiated from biological particles through a combination of high and low frequency measurements. ${ }^{53,56,61,62,65}$ In impedance flow cytometry, particles are typically $1-25 \mu \mathrm{m} .{ }^{51-53,55-58,60-64}$ For microplastic analysis, it is necessary to expand impedance spectroscopy to cover a larger size range $(1-1000 \mu \mathrm{m}){ }^{67}$ Here, we demonstrate the utility of impedance spectroscopy for microplastic detection in tap water in the laboratory, the first step toward developing a high-throughput, in situ sensor for microplastic quantification in freshwater bodies.

\section{EXPERIMENTAL SECTION}

Samples. Twenty neutral density polyethylene (PE) beads (Cospheric) in each of the six size ranges $(212-250,300-355$, $425-500,500-600,600-710$, and $850-1000 \mu \mathrm{m})$ were used as microplastic samples (Table S1). Eight biological specimens [brine shrimp eggs $(210-270 \mu \mathrm{m})$, brine shrimp nauplii $(260-320 \mu \mathrm{m})$, volvox globator colonies $(90-430 \mu \mathrm{m})$, marine copepods $(430-610$ $\mu \mathrm{m})$, moina $(570-780 \mu \mathrm{m})$, daphnia pulex $(890-1200 \mu \mathrm{m})$, teff $(720-920 \mu \mathrm{m})$, and poppy seeds $(980-1200 \mu \mathrm{m})]$, covering the same size range as the microplastics, were used as representative biological materials that could be found in a natural water body (Figure 1, Table S1, Figure S1, Text S1). All sizes are reported in terms of equivalent spherical diameter (ESD), the diameter of a sphere of equivalent volume. The range in ESD of the biological samples was estimated by measuring 15 samples of each type. Biological samples were imaged on a $3 \mathrm{~mm}$ gridded filter and were modeled as ellipsoids, assuming a depth measurement equal to the minor axis.

Impedance Spectroscopy Setup and Electronics. A flow cell with parallel plate electrodes and clear sides was constructed using two custom gold-plated circuit boards (PCBWay), acrylic (1.9 mm thickness, McMaster-Carr) and 5 min epoxy (Loctite) (Figure S2). A rectangular brass tube $(1.7 \mathrm{~mm} \times 4 \mathrm{~mm}$ ID, McMaster-Carr $)$ was used for tubing connection. A pair of transmit $(5 \times 58 \mathrm{~mm})$ and receive $(5 \times 5 \mathrm{~mm})$ gold-plated electrodes were used for impedance measurements, spaced $2 \mathrm{~mm}$ apart. Grounded electrodes were placed on each side of the receive electrode to improve electric field uniformity, as described in Gawad et al. ${ }^{68}$ Flexible PVC tubing connected the flow cell to the sample funnel and to the sample recovery sieve $(53 \mu \mathrm{m})$. The funnel was placed above the flow cell, allowing the flow to be entirely gravity-fed, with the water level 220$270 \mathrm{~mm}$ above the flow cell (Figure 2). The average flow rate was 103 $\pm 8 \mathrm{~mL} / \mathrm{min}$. The flow rate was quantified by measuring the volume

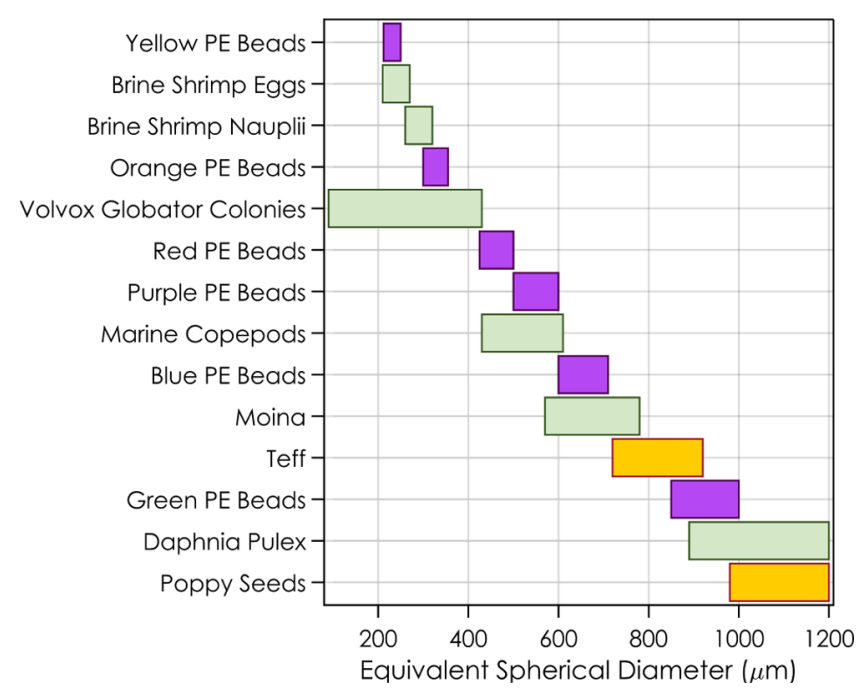

Figure 1. Six sizes of microplastics were tested (purple bars). Representative biological specimens consisting of organisms (green bars) and seeds (yellow bars) were selected within the same size range.

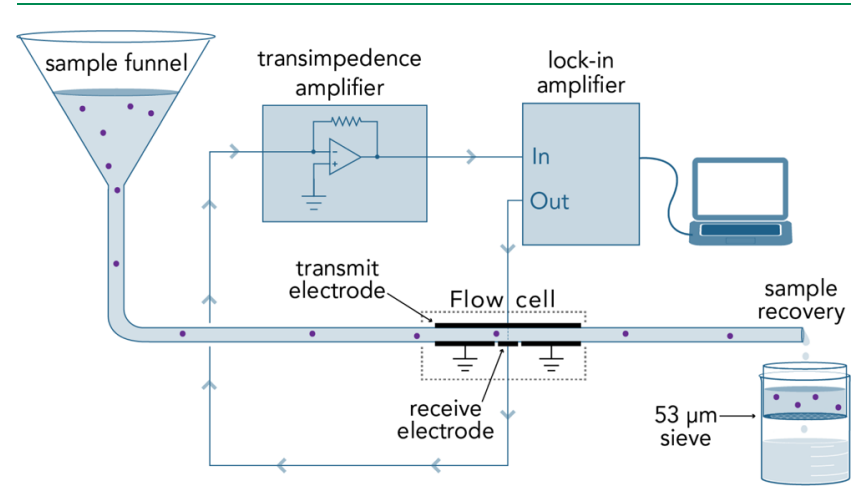

Figure 2. Impedance spectroscopy experimental setup. To conduct an experiment, particle-spiked samples were added to the sample funnel. Clean water (degassed $53 \mu \mathrm{m}$ filtered tap water) was added periodically to maintain the water level until all particles were flushed through. The flow was gravity fed. A transimpedance amplifier and a lock-in amplifier were used to monitor the impedance between the transmit and receive electrodes at six frequencies simultaneously. The changes in impedance due to particles passing through the flow cell were detected in post-processing. After passing through the flow cell, the particle-spiked water was filtered through a $53 \mu \mathrm{m}$ sieve, and microplastics were visually counted.

of the water output by the sensor over four minutes, repeated three times. The particle velocity was nominally $0.3 \mathrm{~m} / \mathrm{s}$ through the flow cell. To determine the particle velocity, both receive electrodes (Figure S2) were used to measure the flow spiked with 850-1000 $\mu \mathrm{m}$ plastic beads. The time delay between detections was estimated via cross-correlation and velocity was calculated using the distance between the electrodes $(21 \mathrm{~mm})$.

A lock-in amplifier (HF2LI-MF, Zurich Instruments) was used to supply a test voltage to the transmit electrode consisting of the superposition of six sinusoids: $215 \mathrm{mV}_{\mathrm{pk}}$ at $10 \mathrm{kHz}, 200 \mathrm{mV}_{\mathrm{pk}}$ at 90 $\mathrm{kHz}, 200 \mathrm{mV}_{\mathrm{pk}}$ at $200 \mathrm{kHz}, 200 \mathrm{mV}_{\mathrm{pk}}$ at $500 \mathrm{kHz}, 190 \mathrm{mV}_{\mathrm{pk}}$ at 1.1 $\mathrm{MHz}$, and $120 \mathrm{mV}_{\mathrm{pk}}$ at $3 \mathrm{MHz}$, with zero DC offset. The voltages were selected to avoid amplifier saturation and maintain uniform baseline levels. The current passing through the water to the receive electrode was measured using a transimpedance amplifier (HF2TA, Zurich Instruments) with $10 \mathrm{k} \Omega$ gain, with its output voltage monitored by the lock-in amplifier. The lock-in amplifier was set for $50 \Omega$ input impedance, DC coupling, an input voltage range of $1 \mathrm{~V}$, 
and sampled at $1.799 \mathrm{kSa} / \mathrm{s}$ with a 4th order low-pass filter with $3 \mathrm{~dB}$ (a $99.77 \mathrm{~Hz}$ cutoff frequency. LabOne (Zurich Instruments) was used to control the lock-in amplifier and record in-phase and $90^{\circ}$ phaseshifted measurements of the transimpedance amplifier output voltage. All data processing used MATLAB (Version 2020a). The procedures to calculate the impedance, identify and subtract the time-varying baseline impedance, and detect the impedance changes due to particles are described in the Supporting Information (Text S2-S3 Figures S3-S5).

Experimental Procedure. All experiments were conducted using tap water, degassed in a glass beaker using a magnetic spin plate for $>30 \mathrm{~min}$, and then filtered to $53 \mu \mathrm{m}$. Prior to each experimental run, the flow-through components of the impedance setup were flushed with $\sim 1 \mathrm{~L}$ of clean water with care to avoid bubbles. For all measurements, the flow of clean water was started and the impedance was monitored using LabOne live-view. When the initial transients diminished, the data recording was started and a particle-spiked sample was added to the funnel (Figure 2). The sample vial was rinsed into the funnel and visually inspected. The water level was maintained in the funnel by periodically adding clean water until all particles were no longer visually present, taking 2-16 min. The hydrophobicity of the smaller beads $(<500 \mu \mathrm{m})$ caused them to float; therefore, a small amount of surfactant (Dawn Dish Soap) was added to the water via a wooden applicator to reduce surface tension, resulting in the suspension of the beads. The soap addition did not impact the impedance appreciably. After passing through the flow cell, particles were collected on the sample recovery sieve. The microplastic count was confirmed visually, using a microscope for the $212-250 \mu \mathrm{m}$ beads. A blank was run with clean tap water before experimentation. After the particle experiments, bubbles, created in clean water using a syringe, were injected into the flow to assess crosssensitivity.

Particle Classification Using k-Nearest Neighbors. Particle detections were classified as plastics, biology, or bubbles using the $\mathrm{k}$ nearest neighbors (k-NN) classification. Two weighted k-NN classifiers were compared: a 12-dimensional (12-D) k-NN, trained using the change in real and imaginary impedance at all six frequencies, and a 2-dimensional (2-D) k-NN, trained using the change in the magnitude of the impedance at $10 \mathrm{kHz}$ and $1.1 \mathrm{MHz} .2$ $\mathrm{D}$ k-NN was used to evaluate if fewer parameters could be measured in future iterations. The two parameters were selected by systematically comparing scatter plots of pairs of measurements and selecting the combination with the greatest separation. Both k-NNs were trained using the detections in the interquartile range for each experiment, using the MATLAB Classification Learner App and 10fold cross-validation. Default settings for training a weighted k-NN in MATLAB were used: ten nearest neighbors, kd-tree method for neighbor search, Euclidean distance, distance weighted by the squared inverse, data standardization enabled, and default cost matrix. The interquartile range was determined using a measurement proportional to the ESD of the detected particle, the cube root of the change in real impedance at $10 \mathrm{kHz}$. All detections were classified using the trained models. The true positive rate for detecting microplastics, the false positive rate due to biology misclassification, and the false positive rate due to bubble misclassification were then calculated (Text S4).

Outlier Removal in Microplastic Experiments and the Recovery Rate. Impedance changes, due to disturbances such as entrained bubbles, vibration, electrical noise, imperfect baseline identification, or microfiber contamination, can appear as extra detections. To ensure that all detections in microplastic experiments were due to the added microplastic beads and not disturbances, an outlier detection algorithm (Text S5) was used to find detections with anomalous size, based on the ESD, for each experiment run. The outliers were assumed to be due to disturbances and analyzed separately. All other detections were assumed to be true detections of microplastics and used to evaluate the true positive rate of the two kNN classifiers. The recovery rate is the number of true microplastic detections divided by the total number of microplastics used in an experiment $(n=20)$, expressed as a percent (Text S4).
Sizing Microplastics with Impedance. The change in the real part of the impedance at low frequency should be proportional to particle volume. ${ }^{58,61}$ Therefore, the cube root of the real impedance change should be proportional to the ESD. To obtain a conversion factor needed to change between impedance measurements and the microplastic ESD, a line was fit between the microplastic diameter and the cube root of the change in real impedance at $10 \mathrm{kHz}$ with outliers removed (Text S6). The conversion factor was applied to the microplastic detections to compare the measured size distribution to the manufacturer specifications.

\section{RESULTS AND DISCUSSION}

\section{Differentiating Microplastics from Biological Materi-} als. Using the impedance setup and the 12-D k-NN classifier, microplastics could be differentiated from biological particles (Tables S2-S5). Zero plastic detections were misclassified as biology. The false positive rate due to biology was $1 \%$ as only three biology detections out of 285 total detections were misclassified as plastic. Plastic and biological detections could be distinguished using the complex impedance change at any one of the six measured frequencies (Figure S6). Biological particles had greater impact on the imaginary component of the impedance (Figure S6). The cellular composition of biological particles could explain this increased imaginary component since cells have additional capacitance from membrane and cytoplasm construction. ${ }^{61,62}$

2-D k-NN was trained using two measurements, the change in the magnitude of the baseline impedance at $10 \mathrm{kHz}$ and at $1.1 \mathrm{MHz}$, and achieved nearly the same performance as 12-D k-NN (Tables S2, S6-S8). Two biological detections were misclassified as plastic, for a false positive rate of $1 \%$, and one plastic detection was misclassified as a bubble. The change in the magnitude of the impedance efficiently captures both the magnitude and angle of the complex impedance change in a single measurement (Figure S7). At 1.1 MHz, the direction of complex impedance change was generally in the opposite direction for biological and plastic detections (Figure S6). Consequently, the change in the magnitude of the impedance at $1.1 \mathrm{MHz}$ was typically negative for biological detections and positive for plastics (Figure 3). At $10 \mathrm{kHz}$, seeds and organisms had distinct impedance responses (Figure S6), and the magnitude of the impedance change was typically positive for seeds and plastics and negative for organisms (Figure 3).

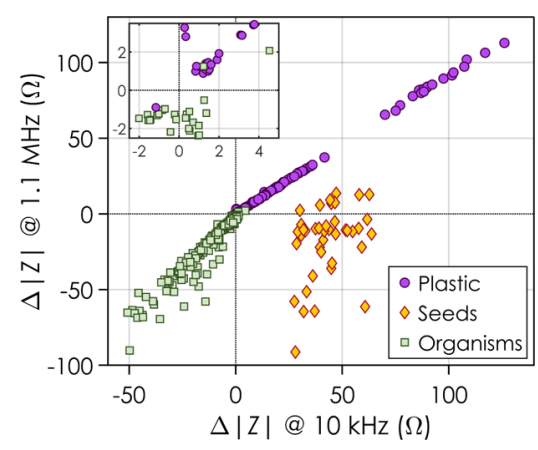

Figure 3. Differentiation of microplastics and biological samples (seeds and live organisms) using the change in the magnitude of the baseline impedance at high $(1.1 \mathrm{MHz})$ and low $(10 \mathrm{kHz})$ frequencies. The inset shows little overlap at small amplitudes. All detections are shown here, including all detections later identified as outliers. The plastic detection clustering with organisms in the inset was later determined to be an outlier. 
A simple quadrant-based differentiation scheme was possible with measurements of the change in the magnitude of the impedance at $10 \mathrm{kHz}$ and $1.1 \mathrm{MHz}$ (Figure 3). Microplastics clustered in the first quadrant and organisms clustered separately in the third quadrant. Seeds could be distinguished from microplastics as a lower impedance change was measured at $1.1 \mathrm{MHz}$ than was measured at $10 \mathrm{kHz}$. Microplastics could be distinguished from organisms as the organisms showed a positive impedance change at $10 \mathrm{kHz}$. Using this quadrantbased scheme, one microplastic detection would be misclassified as an organism and two biological detections would be misclassified as plastic for the same false positive rate as the k-NNs (Figure 3 inset). This simple logic could be implemented on a low-cost microcontroller in the future allowing for real-time microplastic sorting.

Differentiating Microplastics from Bubbles. A potential limitation of impedance spectroscopy is the misclassification of bubbles as plastics since air and plastics exhibit similar electrical properties (dielectric constant $\sim 1$ for air, $\sim 2.3$ for $\mathrm{PE}^{69}$ ), whereas cells have a nonconducting membrane layer surrounding the conductive cytoplasm, which acts like an additional capacitor. ${ }^{61,62}$ Using 12-D k-NN and 2-D k-NN, bubbles were differentiated from microplastics with a false positive rate of $1 \%$ ( 1 bubble detection of 73 total was misidentified as a microplastic) (Tables S2-S8). Using the change in the magnitude of the impedance, 42 large amplitude $(>200 \Omega$ ) bubble detections fell in the same quadrant as plastics (Figure S8). A different combination of parameters than those used in 2-D k-NN may offer better differentiation, as the complex impedance change at all frequencies showed separation of the majority of plastic and bubble detections, particularly at $10 \mathrm{kHz}$ and $3 \mathrm{MHz}$ (Figure S6). While these detections were differentiated well with both k-NNs, given their amplitude, it is possible that the majority of bubbles tested were larger than the microplastics used, and the results may change with different size bubbles. Although bubbles were purposely injected into the flow, no control or independent measure of bubble size was possible. Controlled experiments with a known bubble size would confirm if bubbles of all sizes can be differentiated from microplastics.

Measurement of the Microplastic Size by Impedance Spectroscopy. Impedance spectroscopy was used to measure the size of each detected microplastic. A linear relationship between the microplastic sample diameter and the cube root of the real impedance change at $10 \mathrm{kHz}$ was observed (Figure S9), as expected. ${ }^{58,61}$ The conversion factor from the fit was $207 \mu \mathrm{m} \Omega^{-1 / 3}$. Using the conversion factor, overall agreement was observed between the impedance measurements of the microplastic size distribution and the manufacturer specifications (Figure S10). Greater variability was observed in the size measurements via impedance spectroscopy, with an average increase of $17 \mu \mathrm{m}$ in the observed ESD range (Figure S10, Table S9). Variability in impedance-based size measurements could be reduced by using differential measurements ${ }^{52,58}$ and by ensuring that particles are centered in the flow, by using hydrodynamic, $^{70}$ acoustic, $^{71}$ or inertial focusing. ${ }^{72}$ Focusing techniques also order particles longitudinally, reducing the chance that multiple particles pass through the flow cell simultaneously. ${ }^{70,72}$

Recovery Rate. The 12-D k-NN and 2-D k-NN classified microplastics with true positive rates of 100 and 99\%, respectively (Table S2). Although we expected 120 microplastic detections, 116 detections were measured, of which 8 were identified as outliers, for a total of 108 true microplastic detections. Of the 12 microplastics that were not detected, 9 were from the smallest size range $(212-250 \mu \mathrm{m})$ used. The overall recovery rates using the total number of true particle detections classified as plastic over all experiments were 90 and $89 \%$ for $12-\mathrm{D} \mathrm{k}-\mathrm{NN}$ and $2-\mathrm{D} \mathrm{k}-\mathrm{NN}$, respectively. Using $12-\mathrm{D}$ $\mathrm{k}-\mathrm{NN}$, the recovery rate for correctly detecting and identifying a particle as a microplastic was $\geq 90 \%$ for the microplastics $\geq 300 \mu \mathrm{m}$ in size and $55 \%$ for the $212-250 \mu \mathrm{m}$ size range, demonstrating that the impedance sensor can be used for the accurate counting of microplastics in the 300-1000 $\mu \mathrm{m}$ size range (Figure 4, Table S10). Using 2-D k-NN, only one plastic detection was misclassified in the $212-250 \mu \mathrm{m}$ size range, and a high recovery rate was still achieved (Figure 4, Table S10).

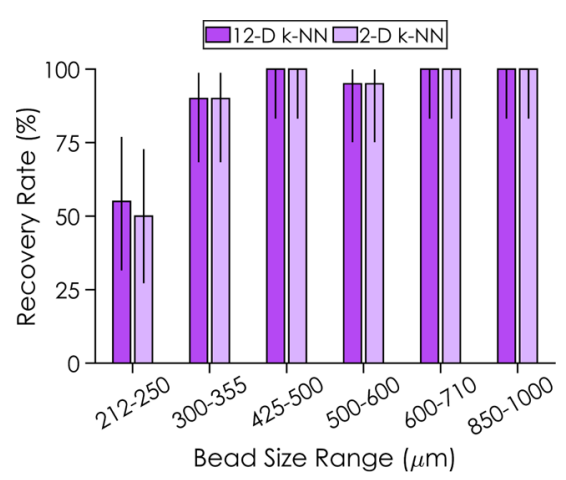

Figure 4. Recovery rate was calculated based on the number of microplastics identified with outliers removed divided by the number of microplastics placed in the flow $(n=20)$. The error bars represent the $95 \%$ confidence limits obtained by treating each experiment as a set of 20 Bernoulli trials (Text S7). 2-D k-NN had nearly the same performance identifying microplastics as $12-\mathrm{D} \mathrm{k}-\mathrm{NN}$.

The 7 outlier detections were classified differently using 12D k-NN versus 2-D k-NN (Tables S4, S7). Using 12-D k-NN, 5 outliers were identified as plastics, whereas only 1 was identified as plastic using 2-D k-NN. These detections could be microfibers or bubbles. Microfibers accumulated on the sample recovery filter throughout experimentation but could not be quantified visually due to the minute size of the microfibers. Small bubbles were observed attached to the hydrophobic microplastic beads and could have separated due to acceleration in the flow cell. No detections were recorded in the blank experiment. Future testing will include a secondary method of particle detection (e.g. optical) to assess whether these detections are due to interfering particles or technique limitations.

All of the outlier detections that were classified as microplastics were smaller than $250 \mu \mathrm{m}$ (Figure S10, Table S11). Similar detections due to disturbances could have occurred in the $212-250 \mu \mathrm{m}$ experiment and would not have been detected by the size-sensitive outlier removal process. To evaluate the recovery rate, it was necessary to estimate how many disturbance-related detections could have occurred in the $212-250 \mu \mathrm{m}$ experiment. The plastic-identified disturbances were modeled as a Poisson process with a constant rate across all microplastic experiments. The rate was estimated using the experiment times and the number of outlier plastic detections in the plastic experiments $>300 \mu \mathrm{m}$ (Text S8).

With $95 \%$ confidence, the number of true microplastic detections in the $212-250 \mu \mathrm{m}$ experiment was $9 \pm 2$ using 12 - 
D k-NN for identification and $9 \pm 1$ using 2-D k-NN (Table S12). Given the low recovery rate and presence of disturbancecaused outliers, an improved electrode design is needed for accurate quantification of plastics $<300 \mu \mathrm{m}$. The recovery rate for smaller plastics could be increased using smaller electrodes and a narrower gap. This design change could allow for the smaller microplastics to be more successfully identified, as demonstrated via impedance flow cytometry. ${ }^{53,56,61,62,65}$

Implications. Accurately counting microplastics is critical for robust measurements of microplastics in the environment. This is one of the first demonstrations of flow-through counting and sizing of microplastics with differentiation of plastic and biological materials. Flow-through microplastic detection has been demonstrated via Raman spectroscopy ${ }^{47-49}$ and resistive pulse detection; ${ }^{50}$ however, Raman spectroscopybased techniques did not measure the full fluid flow, allowing particles to flow through unanalyzed and therefore inaccurately counting microplastics. ${ }^{47-49}$ With impedance spectroscopy, measurements were high-throughput, with each particle in the flow cell for milliseconds. Since the impedance measurements are real-time, this approach could be used to divert microplastics for further analysis. The simplicity of the measurement and the ability to differentiate biological and plastic particles make the development of an in situ instrument possible. Several other particle types, such as different polymers, biofouled samples, irregular shapes, and fibers, as well as different water conductivity need to be examined prior to deploying this approach in the field. To sample complex environmental mixtures, careful hydrodynamic design is necessary to ensure that particles of different densities remain entrained in the flow.

\section{ASSOCIATED CONTENT}

\section{(s) Supporting Information}

The Supporting Information is available free of charge at https://pubs.acs.org/doi/10.1021/acssensors.0c02223.

Description of samples; sample preparation details; flow cell details; calculation of impedance from lock-in measurements; circuit diagram; data processing description; example raw impedance signal; example peak shapes; calculation of figures of merit; outlier removal procedure; microplastic sizing; overall differentiation results; differentiation with 12-D k-NN results; real and imaginary impedance changes; differentiation with 2-D $\mathrm{k}-\mathrm{NN}$ results; illustrations of the change in impedance on the complex plane; impedance change results including bubbles; linear fit between the cube root of the real impedance data at $10 \mathrm{kHz}$ and the bead diameter; size distribution measured by the sensor; measured ESD of microplastics; recovery rate data; measured ESD of outlier plastic detections; statistical analysis of spike and recovery experiments; Poisson model for disturbance detections in the 212-250 $\mu \mathrm{m}$ experiment; and disturbance model results (PDF)

\section{AUTHOR INFORMATION}

\section{Corresponding Author}

Anna P. M. Michel - Department of Applied Ocean Physics and Engineering, Woods Hole Oceanographic Institution, Woods Hole, Massachusetts 02543, United States; ๑ orcid.org/0000-0001-9319-0592; Email: amichel@ whoi.edu

\section{Author}

Beckett C. Colson - Department of Applied Ocean Physics and Engineering, Woods Hole Oceanographic Institution, Woods Hole, Massachusetts 02543, United States; Department of Mechanical Engineering, Massachusetts Institute of Technology, Cambridge, Massachusetts 02139, United States; MIT-WHOI Joint Program in Oceanography/ Applied Ocean Science \& Engineering, Cambridge and Woods Hole, Massachusetts, United States

Complete contact information is available at:

https://pubs.acs.org/10.1021/acssensors.0c02223

\section{Funding}

The authors thank the Richard Saltonstall Charitable Foundation and the National Academies Keck Futures Initiative (NAKFI DBS13) for their funding support.

\section{Notes}

The authors declare no competing financial interest.

\section{ACKNOWLEDGMENTS}

The authors thank A. Morrison for her assistance with measuring the biological specimens. The authors thank $\mathrm{H}$. White for her critical feedback on the manuscript. The authors thank A. Solow for suggestions and feedback on statistical analysis. The authors thank the WHOI Microplastics Catalyst program for their support.

\section{REFERENCES}

(1) Burns, E. E.; Boxall, A. B. A. Microplastics in the Aquatic Environment: Evidence for or against Adverse Impacts and Major Knowledge Gaps: Microplastics in the Environment. Environ. Toxicol. Chem. 2018, 37, 2776-2796.

(2) GESAMP. "Sources, Fate and Effects of Microplastics in the Marine Environment: Part Two of a Global Assessment" Kershaw, P. J., Rochman, C. M., Eds. (IMO/FAO/UNESCO-IOC/UNIDO/WMO/ IAEA/UN/UNEP/UNDP Joint Group of Experts on the Scientific Aspects of Marine Environmental Protection). Rep. Stud. GESAMP No. 93, 2016; p 220.

(3) Hale, R. C.; Seeley, M. E.; La Guardia, M. J.; Mai, L.; Zeng, E. Y. A Global Perspective on Microplastics. J. Geophys. Res.: Oceans 2020, 125, No. e2018JC014719.

(4) Koelmans, A. A.; Mohamed Nor, N. H.; Hermsen, E.; Kooi, M.; Mintenig, S. M.; De France, J. Microplastics in Freshwaters and Drinking Water: Critical Review and Assessment of Data Quality. Water Res. 2019, 155, 410-422.

(5) Koelmans, A. A.; Besseling, E.; Foekema, E.; Kooi, M.; Mintenig, S.; Ossendorp, B. C.; Redondo-Hasselerharm, P. E.; Verschoor, A.; van Wezel, A. P.; Scheffer, M. Risks of Plastic Debris: Unravelling Fact, Opinion, Perception, and Belief. Environ. Sci. Technol. 2017, 51, 11513-11519.

(6) Kooi, M.; Koelmans, A. A. Simplifying Microplastic via Continuous Probability Distributions for Size, Shape, and Density. Environ. Sci. Technol. Lett. 2019, 6, 551-557.

(7) Law, K. L. Plastics in the Marine Environment. Annu. Rev. Mar. Sci. 2017, 9, 205-229.

(8) Filella, M. Questions of Size and Numbers in Environmental Research on Microplastics: Methodological and Conceptual Aspects. Environ. Chem. 2015, 12, 527-538.

(9) Rochman, C. M.; Brookson, C.; Bikker, J.; Djuric, N.; Earn, A.; Bucci, K.; Athey, S.; Huntington, A.; Mcllwraith, H.; Munno, K.; et al. Rethinking Microplastics as a Diverse Contaminant Suite. Environ. Toxicol. Chem. 2019, 38, 703-711.

(10) Isobe, A.; Buenaventura, N. T.; Chastain, S.; Chavanich, S.; Cózar, A.; DeLorenzo, M.; Hagmann, P.; Hinata, H.; Kozlovskii, N.; Lusher, A. L.; et al. An Interlaboratory Comparison Exercise for the 
Determination of Microplastics in Standard Sample Bottles. Mar. Pollut. Bull. 2019, 146, 831-837.

(11) Maximenko, N.; Corradi, P.; Law, K. L.; Van Sebille, E.; Garaba, S. P.; Lampitt, R. S.; Galgani, F.; Martinez-Vicente, V.; Goddijn-Murphy, L.; Veiga, J. M. Toward the Integrated Marine Debris Observing System. Front. Mar. Sci. 2019, 6, 447.

(12) Primpke, S.; Christiansen, S. H.; Cowger, W.; De Frond, H.; Deshpande, A.; Fischer, M.; Holland, E.; Meyns, M.; O’Donnell, B. A.; Ossmann, B.; et al. Critical Assessment of Analytical Methods for the Harmonized and Cost Efficient Analysis of Microplastics. Appl. Spectrosc. 2020, 79, 1012-1047.

(13) Shim, W. J.; Hong, S. H.; Eo, S. E. Identification Methods in Microplastic Analysis: A Review. Anal. Methods 2017, 9, 1384-1391.

(14) Hurley, R.; Woodward, J.; Rothwell, J. J. Microplastic Contamination of River Beds Significantly Reduced by CatchmentWide Flooding. Nat. Geosci. 2018, 11, 251-257.

(15) Lebreton, L. C. M.; van der Zwet, J.; Damsteeg, J.-W.; Slat, B.; Andrady, A.; Reisser, J. River Plastic Emissions to the World's Oceans. Nat. Commun. 2017, 8, 15611.

(16) Simon, M.; van Alst, N.; Vollertsen, J. Quantification of Microplastic Mass and Removal Rates at Wastewater Treatment Plants Applying Focal Plane Array (FPA)-Based Fourier Transform Infrared (FT-IR) Imaging. Water Res. 2018, 142, 1-9.

(17) Dris, R.; Gasperi, J.; Saad, M.; Mirande, C.; Tassin, B. Synthetic Fibers in Atmospheric Fallout: A Source of Microplastics in the Environment? Mar. Pollut. Bull. 2016, 104, 290-293.

(18) Zhang, Y.; Kang, S.; Allen, S.; Allen, D.; Gao, T.; Sillanpää, M. Atmospheric Microplastics: A Review on Current Status and Perspectives. Earth-Sci. Rev. 2020, 203, 103118.

(19) Chubarenko, I.; Bagaev, A.; Zobkov, M.; Esiukova, E. On Some Physical and Dynamical Properties of Microplastic Particles in Marine Environment. Mar. Pollut. Bull. 2016, 108, 105-112.

(20) Cook, S.; Chan, H.-L.; Abolfathi, S.; Bending, G. D.; Schäfer, H.; Pearson, J. M. Longitudinal Dispersion of Microplastics in Aquatic Flows Using Fluorometric Techniques. Water Res. 2020, 170, 115337.

(21) Kane, I. A.; Clare, M. A.; Miramontes, E.; Wogelius, R.; Rothwell, J. J.; Garreau, P.; Pohl, F. Seafloor Microplastic Hotspots Controlled by Deep-Sea Circulation. Science 2020, 368, 1140-1145.

(22) Kukulka, T.; Proskurowski, G.; Morét-Ferguson, S.; Meyer, D. W.; Law, K. L. The Effect of Wind Mixing on the Vertical Distribution of Buoyant Plastic Debris. Geophys. Res. Lett. 2012, 39, 7601.

(23) van Sebille, E.; Aliani, S.; Law, K. L.; Maximenko, N.; Alsina, J. M.; Bagaev, A.; Bergmann, M.; Chapron, B.; Chubarenko, I.; Cózar, A.; et al. The Physical Oceanography of the Transport of Floating Marine Debris. Environ. Res. Lett. 2020, 15, 023003.

(24) Hidalgo-Ruz, V.; Gutow, L.; Thompson, R. C.; Thiel, M. Microplastics in the Marine Environment: A Review of the Methods Used for Identification and Quantification. Environ. Sci. Technol. 2012, 46, 3060-3075.

(25) Frère, L.; Paul-Pont, I.; Moreau, J.; Soudant, P.; Lambert, C.; Huvet, A.; Rinnert, E. A Semi-Automated Raman Micro-Spectroscopy Method for Morphological and Chemical Characterizations of Microplastic Litter. Mar. Pollut. Bull. 2016, 113, 461-468.

(26) Lenz, R.; Enders, K.; Stedmon, C. A.; Mackenzie, D. M. A.; Nielsen, T. G. A Critical Assessment of Visual Identification of Marine Microplastic Using Raman Spectroscopy for Analysis Improvement. Mar. Pollut. Bull. 2015, 100, 82-91.

(27) Lusher, A. L.; Welden, N. A.; Sobral, P.; Cole, M. Sampling, Isolating and Identifying Microplastics Ingested by Fish and Invertebrates. Anal. Methods 2017, 9, 1346-1360.

(28) Song, Y. K.; Hong, S. H.; Jang, M.; Han, G. M.; Rani, M.; Lee, J.; Shim, W. J. A Comparison of Microscopic and Spectroscopic Identification Methods for Analysis of Microplastics in Environmental Samples. Mar. Pollut. Bull. 2015, 93, 202-209.

(29) Erni-Cassola, G.; Gibson, M. I.; Thompson, R. C.; ChristieOleza, J. A. Lost, but Found with Nile Red: A Novel Method for Detecting and Quantifying Small Microplastics (1 Mm to $20 \mathrm{Mm}$ ) in Environmental Samples. Environ. Sci. Technol. 2017, 51, 1364113648.
(30) Maes, T.; Jessop, R.; Wellner, N.; Haupt, K.; Mayes, A. G. A Rapid-Screening Approach to Detect and Quantify Microplastics Based on Fluorescent Tagging with Nile Red. Sci. Rep. 2017, 7, 44501.

(31) Shim, W. J.; Song, Y. K.; Hong, S. H.; Jang, M. Identification and Quantification of Microplastics Using Nile Red Staining. Mar. Pollut. Bull. 2016, 113, 469-476.

(32) Stanton, T.; Johnson, M.; Nathanail, P.; Gomes, R. L.; Needham, T.; Burson, A. Exploring the Efficacy of Nile Red in Microplastic Quantification: A Costaining Approach. Environ. Sci. Technol. Lett. 2019, 6, 606-611.

(33) Cabernard, L.; Roscher, L.; Lorenz, C.; Gerdts, G.; Primpke, S. Comparison of Raman and Fourier Transform Infrared Spectroscopy for the Quantification of Microplastics in the Aquatic Environment. Environ. Sci. Technol. 2018, 52, 13279-13288.

(34) Elert, A. M.; Becker, R.; Duemichen, E.; Eisentraut, P.; Falkenhagen, J.; Sturm, H.; Braun, U. Comparison of Different Methods for MP Detection: What Can We Learn from Them, and Why Asking the Right Question before Measurements Matters? Environ. Pollut. 2017, 231, 1256-1264.

(35) Käppler, A.; Fischer, D.; Oberbeckmann, S.; Schernewski, G.; Labrenz, M.; Eichhorn, K.-J.; Voit, B. Analysis of Environmental Microplastics by Vibrational Microspectroscopy: FTIR, Raman or Both? Anal. Bioanal. Chem. 2016, 408, 8377-8391.

(36) Sobhani, Z.; Al Amin, M.; Naidu, R.; Megharaj, M.; Fang, C. Identification and Visualisation of Microplastics by Raman Mapping. Anal. Chim. Acta 2019, 1077, 191-199.

(37) Jung, M. R.; Horgen, F. D.; Orski, S. V.; Rodriguez, C. V.; Beers, K. L.; Balazs, G. H.; Jones, T. T.; Work, T. M.; Brignac, K. C.; Royer, S.-J.; et al. Validation of ATR FT-IR to Identify Polymers of Plastic Marine Debris, Including Those Ingested by Marine Organisms. Mar. Pollut. Bull. 2018, 127, 704-716.

(38) Käppler, A.; Fischer, M.; Scholz-Böttcher, B. M.; Oberbeckmann, S.; Labrenz, M.; Fischer, D.; Eichhorn, K.-J.; Voit, B. Comparison of $\mu$-ATR-FTIR Spectroscopy and Py-GCMS as Identification Tools for Microplastic Particles and Fibers Isolated from River Sediments. Anal. Bioanal. Chem. 2018, 410, 5313-5327.

(39) Löder, M. G. J.; Kuczera, M.; Mintenig, S.; Lorenz, C.; Gerdts, G. Focal Plane Array Detector-Based Micro-Fourier-Transform Infrared Imaging for the Analysis of Microplastics in Environmental Samples. Environ. Chem. 2015, 12, 563-581.

(40) Mintenig, S. M.; Int-Veen, I.; Löder, M. G. J.; Primpke, S.; Gerdts, G. Identification of Microplastic in Effluents of Waste Water Treatment Plants Using Focal Plane Array-Based Micro-FourierTransform Infrared Imaging. Water Res. 2017, 108, 365-372.

(41) Primpke, S.; Dias, P. A.; Gerdts, G. Automated Identification and Quantification of Microfibres and Microplastics. Anal. Methods 2019, 11, 2138-2147.

(42) Primpke, S.; Lorenz, C.; Rascher-Friesenhausen, R.; Gerdts, G. An Automated Approach for Microplastics Analysis Using Focal Plane Array (FPA) FTIR Microscopy and Image Analysis. Anal. Methods 2017, 9, 1499-1511.

(43) Tagg, A. S.; Sapp, M.; Harrison, J. P.; Ojeda, J. J. Identification and Quantification of Microplastics in Wastewater Using Focal Plane Array-Based Reflectance Micro-FT-IR Imaging. Anal. Chem. 2015, 87, 6032-6040.

(44) Fischer, M.; Scholz-Böttcher, B. M. Microplastics Analysis in Environmental Samples-Recent Pyrolysis-Gas ChromatographyMass Spectrometry Method Improvements to Increase the Reliability of Mass-Related Data. Anal. Methods 2019, 11, 2489-2497.

(45) Hermabessiere, L.; Himber, C.; Boricaud, B.; Kazour, M.; Amara, R.; Cassone, A.-L.; Laurentie, M.; Paul-Pont, I.; Soudant, P.; Dehaut, A.; et al. Optimization, Performance, and Application of a Pyrolysis-GC/MS Method for the Identification of Microplastics. Anal. Bioanal. Chem. 2018, 410, 6663-6676.

(46) Zhang, X.; Zhang, H.; Yu, K.; Li, N.; Liu, Y.; Liu, X.; Zhang, H.; Yang, B.; Wu, W.; Gao, J.; et al. Rapid Monitoring Approach for Microplastics Using Portable Pyrolysis-Mass Spectrometry. Anal. Chem. 2020, 92, 4656-4662. 
(47) Kniggendorf, A.-K.; Wetzel, C.; Roth, B. Microplastics Detection in Streaming Tap Water with Raman Spectroscopy. Sensors 2019, 19, 1839.

(48) Takahashi, T.; Liu, Z.; Thevar, T.; Burns, N.; Mahajan, S.; Lindsay, D.; Watson, J.; Thornton, B. Identification of Microplastics in a Large Water Volume by Integrated Holography and Raman Spectroscopy. Appl. Opt. 2020, 59, 5073-5078.

(49) Zhang, C.; Huang, K.-C.; Rajwa, B.; Li, J.; Yang, S.; Lin, H.; Liao, C.-s.; Eakins, G.; Kuang, S.; Patsekin, V.; et al. Stimulated Raman Scattering Flow Cytometry for Label-Free Single-Particle Analysis. Optica 2017, 4, 103-109.

(50) Pollard, M.; Hunsicker, E.; Platt, M. A Tunable ThreeDimensional Printed Microfluidic Resistive Pulse Sensor for the Characterization of Algae and Microplastics. ACS Sens. 2020, 5, $2578-2586$.

(51) Gawad, S.; Schild, L.; Renaud, P. Micromachined Impedance Spectroscopy Flow Cytometer for Cell Analysis and Particle Sizing. Lab Chip 2001, 1, 76.

(52) Gawad, S.; Cheung, K.; Seger, U.; Bertsch, A.; Renaud, P. Dielectric Spectroscopy in a Micromachined Flow Cytometer: Theoretical and Practical Considerations. Lab Chip 2004, 4, 241.

(53) Cheung, K.; Gawad, S.; Renaud, P. Impedance Spectroscopy Flow Cytometry: On-Chip Label-Free Cell Differentiation. Cytometry, Part A 2005, 65, 124-132.

(54) Cheung, K. C.; Di Berardino, M.; Schade-Kampmann, G.; Hebeisen, M.; Pierzchalski, A.; Bocsi, J.; Mittag, A.; Tárnok, A. Microfluidic Impedance-Based Flow Cytometry. Cytometry, Part A 2010, 77A, 648-666.

(55) Morgan, H.; Sun, T.; Holmes, D.; Gawad, S.; Green, N. G. Single Cell Dielectric Spectroscopy. J. Phys. Appl. Phys. 2007, 40, 6170.

(56) Sun, T.; Morgan, H. Single-Cell Microfluidic Impedance Cytometry: A Review. Microfluid. Nanofluidics 2010, 8, 423-443.

(57) Chen, J.; Xue, C.; Zhao, Y.; Chen, D.; Wu, M.-H.; Wang, J. Microfluidic Impedance Flow Cytometry Enabling High-Throughput Single-Cell Electrical Property Characterization. Int. J. Mol. Sci. 2015, 16, 9804-9830.

(58) Spencer, D.; Caselli, F.; Bisegna, P.; Morgan, H. High Accuracy Particle Analysis Using Sheathless Microfluidic Impedance Cytometry. Lab Chip 2016, 16, 2467-2473.

(59) Petchakup, C.; Li, K.; Hou, H. Advances in Single Cell Impedance Cytometry for Biomedical Applications. Micromachines 2017, 8, 87.

(60) Brazey, B.; Cottet, J.; Bolopion, A.; Van Lintel, H.; Renaud, P.; Gauthier, M. Impedance-Based Real-Time Position Sensor for Labon-a-Chip Devices. Lab Chip 2018, 18, 818-831.

(61) Spencer, D.; Morgan, H. High-Speed Single-Cell Dielectric Spectroscopy. ACS Sens. 2020, 5, 423-430.

(62) Clausen, C.; Dimaki, M.; Bertelsen, C.; Skands, G.; RodriguezTrujillo, R.; Thomsen, J.; Svendsen, W. Bacteria Detection and Differentiation Using Impedance Flow Cytometry. Sensors 2018, 18, 3496.

(63) Claudel, J.; Alves De Araujo, A. L.; Nadi, M.; Kourtiche, D. Lab-On-A-Chip Device for Yeast Cell Characterization in LowConductivity Media Combining Cytometry and Bio-Impedance. Sensors 2019, 19, 3366.

(64) Benazzi, G.; Holmes, D.; Sun, T.; Mowlem, M. C.; Morgan, H. Discrimination and Analysis of Phytoplankton Using a Microfluidic Cytometer. IET Nanobiotechnol. 2007, 1, 94.

(65) Hoffman, R. A.; Britt, W. B. Flow-System Measurement of Cell Impedance Properties. J. Histochem. Cytochem. 1979, 27, 234-240.

(66) Zhao, Y.; Zhao, X. T.; Chen, D. Y.; Luo, Y. N.; Jiang, M.; Wei, C.; Long, R.; Yue, W. T.; Wang, J. B.; Chen, J. Tumor Cell Characterization and Classification Based on Cellular Specific Membrane Capacitance and Cytoplasm Conductivity. Biosens. Bioelectron. 2014, 57, 245-253.

(67) Hartmann, N. B.; Hüffer, T.; Thompson, R. C.; Hassellöv, M.; Verschoor, A.; Daugaard, A. E.; Rist, S.; Karlsson, T.; Brennholt, N.; Cole, M.; et al. Are We Speaking the Same Language?
Recommendations for a Definition and Categorization Framework for Plastic Debris. Environ. Sci. Technol. 2019, 53, 1039-1047.

(68) Gawad, S.; Holmes, D.; Benazzi, G.; Renaud, P.; Morgan, H. Impedance Spectroscopy and Optical Analysis of Single Biological Cells and Organisms in Microsystems. In Microengineering in Biotechnology; Hughes, M. P., Hoettges, K. F., Eds.; Methods in Molecular Biology; Humana Press: Totowa, NJ, 2010; Vol. 583, pp 149-182.

(69) Brandrup, J.; Immergut, E. H.; Grulke, E. A.; Abe, A.; Bloch, D. R. Polymer Handbook, (4th ed.); John Wiley \& Sons, 2005.

(70) Rodriguez-Trujillo, R.; Mills, C. A.; Samitier, J.; Gomila, G. Low Cost Micro-Coulter Counter with Hydrodynamic Focusing. Microfluid. Nanofluidics 2007, 3, 171-176.

(71) Grenvall, C.; Antfolk, C.; Bisgaard, C. Z.; Laurell, T. TwoDimensional Acoustic Particle Focusing Enables Sheathless Chip Coulter Counter with Planar Electrode Configuration. Lab Chip 2014, 14, 4629-4637.

(72) Di Carlo, D.; Irimia, D.; Tompkins, R. G.; Toner, M. Continuous Inertial Focusing, Ordering, and Separation of Particles in Microchannels. Proc. Natl. Acad. Sci. U.S.A. 2007, 104, 18892-18897. 